\title{
Prevalência da mutação causadora da paralisia periódica hipercalêmica em equinos da raça Quarto de Milha no Brasil
}

\author{
Prevalence of the hypercalemic periodic paralysis mutation in Quarter Horses in Brazil
}

\author{
Diego José Zanzarini Delfiol ${ }^{\mathrm{I}}$ José Paes de Oliveira-Filho ${ }^{\mathrm{II}}$ Alexandre BattazzaII \\ Carla Pinheiro de Souza ${ }^{I I}$ Peres Ramos Badial ${ }^{I I}$ João Pessoa Araujo Junior ${ }^{\text {III }}$ \\ Alexandre Secorun Borges ${ }^{\mathrm{IV}}$
}

\section{RESUMO}

A paralisia periódica hipercalêmica (HYPP) é uma das principais enfermidades genéticas de caráter dominante que acometem cavalos da raça Quarto de milha (QM). A HYPP é causada por uma mutação pontual no gene SCN4A e, apesar de estar presente nos cavalos QMno Brasil, dados sobre a prevalência da HYPP são escassos. O objetivo deste trabalho foi verificar a prevalência da mutação responsável pela HYPP em cavalos $Q M$, utilizados nas modalidades esportivas de rédeas $(n=160)$, apartação $(n=160)$, tambor e baliza $(n=160)$, corrida $(n=160)$ e conformação $(n=101)$. Foram utilizados DNA sanguíneo dos 741 equinos; o teste genético para enfermidade foi padronizado $e$ as amostras sequenciadas para identificação da mutação no gene alvo. A prevalência de HYPP na população amostrada foi de 4,2\%, sendo que somente na linhagem de conformação foram identificados animais positivos (30,7\%). Medidas de controle mais efetivas devem ser adotadas para diminuir a prevalência da HYPP.

Palavras-chave: cavalos, doença genética, HYPP, gene SCN4A.

\section{ABSTRACT}

Hyperkalemic Periodic Paralysis (HYPP) is one of the major dominant genetic diseases which affect Quarter horses $(Q H)$. The HYPP is caused by a point mutation in the SCN4A gene and despite the presence of HYPP in Brazilian $Q H$, limited data on the disease prevalence are available. The aim of this study was to investigate the HYPP mutation in $Q H$ belonging to reining $(n=160)$, cutting $(n=160)$, barrel racing $(n=160)$, racing $(n=160)$ and halter $(n=101)$ competitive disciplines. Blood DNA from 741 horses were used. Genetic tests were standardized and samples were sequenced to identify the mutation on the target gene. The prevalence of HYPP on the sampled population was $4.2 \%$ and the positive animals $(30.7 \%)$ were only identified in the halter lineage. More effective actions on HYPP control should be done to reduce the disease prevalence.

Key words: gene, horses, genetic disease, HYPP, SCN4A.

\section{INTRODUÇ̃̃O}

A HYPP é uma doença genética autossômica codominante que ocorre devido à substituição de uma citosina por uma guanina no gene SCN4A do canal de sódio no cromossomo 11 , que leva à substituição de uma fenilanina por uma leucina (RUDOLPH et al., 1992).

A HYPP está descrita nas raças QM, Apalloosa e na Paint Horse, sendo que as duas últimas possuem a raça $\mathrm{QM}$ em sua composição, por ser uma enfermidade codominante, cavalos mestiços destas raças também podem ser acometidos (FINNO et al., 2009). A doença não tem predisposição por sexo ou idade (NAYLOR et al., 1992). A mutação afeta principalmente animais de conformação, mas também foi encontrada em QM das linhagens de trabalho e velocidade (TRYON et al., 2009).

Todos os animais portadores da mutação responsável pela HYPP possuem um ancestral em comum, o garanhão "Impressive", muito utilizado na linhagem de

'Faculdade de Medicina Veterinária (FAMEV), Universidade Federal de Uberlândia (UFU), Uberlândia, MG, Brasil.

"Faculdade de Medicina Veterinária e Zootecnia (FMVZ), Universidade Estadual Paulista "Júlio de Mesquita Filho" (UNESP), Botucatu, SP, Brasil.

IIIInstituto de Biociências de Botucatu (IBB), UNESP, Botucatu, SP, Brasil.

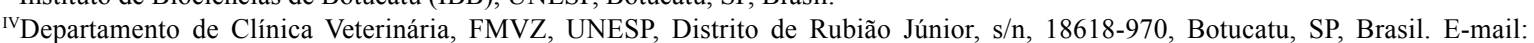
asborges@fmvz.unesp.br. Autor para correspondência. 
conformação e que teve aproximadamente 2.250 filhos (NAYLOR et al., 1992; NAYLOR, 1994a). Por esse motivo, a doença ficou conhecida nos Estados Unidos como "síndrome do Impressive" (NAYLOR, 1994a).

Os equinos com HYPP possuem a musculatura bem desenvolvida, provavelmente devido ao aumento da contração muscular, que pode levar a hipertrofia (NAYLOR, 1994a). Essa característica é desejada em animais de conformação, o que promoveu a propagação da mutação (NAYLOR, 1994b, SPIER, 2006).

Os sinais clínicos da HYPP ocorrem em forma de crises, sendo mais graves nos animais homozigotos para a mutação; animais heterozigotos podem ser assintomáticos ou, em alguns casos, apresentarem crises diárias (RUDOLPH et al., 1992; MEYER et al., 1999). Fasciculações musculares, miotonia, prolapso de terceira pálpebra, fraqueza muscular, dificuldade respiratória, decúbito e morte podem ser sinais clínicos da enfermidade (STEISS \& NAYLOR, 1986; MEYER et al., 1999).

O teste genético para a identificação da mutação é necessário para o diagnóstico da HYPP (RUDOLPH et al., 1992; GARCIA et al., 1996). No Brasil, desde 2004, restrições foram impostas pela Associação Brasileira de Criadores de Cavalo Quarto de Milha (ABQM) para o registro dos animais positivos para a enfermidade, visando diminuir sua incidência (ABQM, 2014).

O objetivo deste trabalho foi verificar a prevalência da mutação no gene $S C N 4 A$, responsável pela HYPP em equinos da raça QM, utilizados em cinco modalidades esportivas no Brasil.

\section{MATERIAL E MÉTODOS}

O tamanho da amostra foi calculado utilizando o software OpenEpi, on line, versão 3. A prevalência da enfermidade foi estimada em 2,2\% (ZORDAN, 2000), com margem de erro de $2 \%$, população de 172.241 cavalos QM registrados no Brasil (ABQM, 2014) e intervalo de confiança de $99 \%$, resultando em um cálculo de amostragem de 325 animais a serem testados. Entretanto, utilizouse um número de animais $(\mathrm{n}=741)$ acima do mínimo necessário para a pesquisa.

Foram utilizadas amostras de DNA obtidas do sangue de 741 cavalos da raça QM, sendo 530 fêmeas e 211 machos, com idade variando entre um e 32 anos, registrados na $\mathrm{ABQM}$, os quais eram provenientes de 41 propriedades. Os animais eram utilizados nas modalidades esportivas de rédeas $(n=160)$, apartação $(n=160)$, tambor e baliza $(n=160)$, corrida $(n=160)$ e conformação $(\mathrm{n}=101)$.
As amostras de sangue foram colhidas em tubos com EDTA, e a extração do DNA sanguíneo foi realizada utilizando o Ilustra ${ }^{\mathrm{TM}}$ Blood GenomicPrep Mini Spin Kit (GE Healthcare), de acordo com o protocolo recomendado pelo fabricante. Após a extração, o DNA foi testado para pureza (A260/280) e concentração no NanoDrop ${ }^{\circledR} 2000$ spectrophotometer (Thermo Scientific ${ }^{\mathrm{TM}}$, DE, USA). Para serem utilizadas na pesquisa, as amostras deviam apresentar relação A260/A280 entre 1,8 e 2,0 e concentração mínima de $20 \mathrm{ng} \mu \mathrm{l}^{-1}$.

Apartir da sequência do gene $S C N 4 A$ equino (Gene ID: 100049793) depositada no Genbank ${ }^{\mathrm{TM}}$, foram desenhados oligonucleotídeos iniciadores (SCN4A-F, 5' - ACGAAGCAGGTGTTCGACAT-3' e SCN4A-R, 5' ATTCACGTGTGTGCAGGCAA-3') utilizando o programa Primer Express $^{\circledR}$ (Life Technologies $^{\mathrm{TM}}$ ). Os iniciadores amplificaram um produto de 441 pares de base, que continha a mutação previamente descrita como responsável pela HYPP.

As reações de PCR foram padronizadas para volume final de $25 \mu \mathrm{L}$, contendo $2 \mu \mathrm{L}$ do DNA extraído, $12,5 \mu \mathrm{L}$ da enzima GoTaq ${ }^{\circledR}$ Green Master Mix, 2x (Promega $\left.{ }^{\mathrm{TM}}\right), 300 \mathrm{nM}$ de cada oligonucleotídeo iniciador e água "nuclease-free" q.s.p. A programação de termociclagem foi de $95^{\circ} \mathrm{C}$

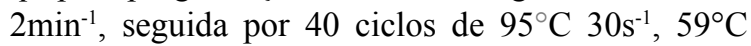
$1 \mathrm{~min}^{-1}$ e $72^{\circ} \mathrm{C} 1 \mathrm{~min}^{-1}$ e extensão final de $72^{\circ} \mathrm{C} 7 \mathrm{~min}^{-1}$.

O tamanho dos produtos amplificados foi verificado por eletroforese (Major Science, Saratoga, CA, USA) em gel de agarose a 1,5\%, corado com GelRed ${ }^{\mathrm{TM}}$ (Biotium, Halward, CA, USA) e comparados com o marcador de peso molecular LowRanger 100pb DNA ladder (Norgen ${ }^{\mathrm{TM}}$, BioTek Corporation, Ontario, Canada).

As amostras amplificadas foram purificadas com o NucleoSpin ${ }^{\circledR}$ Gel and PCR clean-up (MachereyNagel $^{\circledR}$, Duren, Alemanha), conforme a recomendação do fabricante. Após a purificação, $3 \mu \mathrm{L}$ de cada uma das amostras foram submetidas à nova eletroforese em gel de agarose 1,5\%, corado com GelRed ${ }^{\mathrm{TM}}$ (Biotium, Halward, CA, USA) e $2 \mu \mathrm{L}$ foram submetidos à leitura no espectrofotômetro BioPhotometer (Eppendorf ${ }^{\mathbb{B}}$, Hamburg, Germany), para confirmação da presença do produto amplificado e verificação da qualidade e quantidade do material purificado.

Em seguida, $10 \mu \mathrm{L}$ de produto de PCR purificado com $5 \mu \mathrm{L}$ do oligonucleotídeo iniciador SCN4A-F foram submetidos ao sequenciamento direto, usando o BigDye ${ }^{\circledR}$ Terminator v3.1 Cycle Sequencing Kit (Life Technologies) e o sequenciador ABI 3500 Genetic Analyzer (Life Technologies). Após o sequenciamento, o controle de qualidade 
das sequências e dos eletroferogramas obtidos foi realizado utilizando o software Sequencing Analysis 5.3.1 (Applied Biosystems, Foster City, CA, USA). Em uma segunda etapa, as sequências e eletroferogramas foram novamente analisadas utilizando o programa Sequencher 5.1 (Gene Code Corporation) para verificação da sequência de nucleotídeos.

Após os procedimentos previamente descritos, foi possível identificar os genótipos de cada indivíduo para o gene alvo e assim determinar a prevalência da mutação no gene $S C N 4 A$ na população amostrada. Os resultados estão apresentados de maneira descritiva.

\section{RESULTADOS}

A prevalência da mutação no gene $S C N 4 A$ responsável pela HYPP foi de 4,2\%. Dos 741 animais testados, 31 possuíam a mutação, sendo 29 cavalos heterozigotos e dois homozigotos. Todos os animais positivos eram da linhagem de conformação; a prevalência nesta modalidade foi de 30,7\% (Tabela 1).

Dos 101 animais da linhagem de conformação amostrados, 48 (47,5\%) nasceram até o ano de 2004 (ano em que restrição para o registro dos animais positivos foi adotada) e $53(52,5 \%)$ nasceram a partir de 2005. Dos 31 animais identificados com a mutação responsável pela HYPP, 11 (35,5\%) nasceram até 2004 e $20(64,5 \%)$ nasceram a partir de 2005 . A prevalência da enfermidade foi de $22,9 \%$ para os animais nascidos até 2004 e de $37,7 \%$ para os nascidos a partir de 2005.

Das 41 propriedades visitadas, em 13, foram colhidas amostras de cavalos da linhagem de conformação. Destes 13 locais, em sete $(53,8 \%)$, havia animais portadores da mutação. Em um dos locais, havia apenas um cavalo da raça QM e este foi positivo para HYPP. Excluindo este local, a prevalência de animais positivos variou entre $15 \%$ e $50 \%$, nas propriedades onde a mutação foi identificada.

\section{DISCUSSÃ̃}

A prevalência da mutação responsável pela HYPP encontrada neste estudo foi de $4,2 \%$, valor maior que os $2,2 \%$ descritos no Brasil por ZORDAN, (2000), autor este que realizou o teste em 182 cavalos e encontrou quatro heterozigotos para HYPP, porém não mencionou à qual linhagem pertenciam os cavalos testados. Se considerarmos o erro padrão de $2 \%$, os resultados dos trabalhos foram semelhantes. Nos Estados Unidos, TRYON et al. (2009) identificaram $1,5 \%$ e $5 \%$ de prevalência em um grupo QM e Paint Horses, respectivamente, sem diferenciar por modalidade esportiva.

Não foram identificados animais positivos para HYPP nas modalidades esportivas de rédeas, apartação, tambor e baliza e corrida. TRYON et al. (2009) também não encontraram animais de rédeas, apartação e corrida positivos; na modalidade de tambor e baliza, esses autores identificaram apenas um animal $(1,3 \%)$ com a mutação. Esses resultados indicam uma alta concentração de HYPP nos cavalos de conformação.

Ao testarem para HYPP os cavalos QM mais pontuados na classificação da "American Quarter Horse Association" na modalidade de conformação, TRYON et al. (2009) encontraram uma prevalência de $56,4 \%$, resultado que está acima dos 30,7\% encontrados neste estudo, no qual os animais não foram selecionados pelo desempenho esportivo. Uma das principais características fenotípicas avaliadas nos animais durante as provas de conformação é a musculosidade (NAYLOR, 1994a). Os equinos com HYPP possuem a musculatura bem desenvolvida, provavelmente, devido ao aumento da contração muscular, que pode levar à hipertrofia. Os bons resultados em competições acarretaram a seleção dos animais positivos para HYPP (NAYLOR, 1994b), justificando a maior prevalência encontrada por TRYON et al. (2009), quando comparado ao presente estudo.

Tabela 1 - Animais normais e portadores da mutação no gene $S C N 4 A$ causadora da paralisia periódica hipercalêmica.

\begin{tabular}{llllc}
\hline Modalidade esportiva & $\mathrm{N}$ & $\mathrm{C} / \mathrm{C}(\%)$ & $\mathrm{C} / \mathrm{G}(\%)$ & $\mathrm{G} / \mathrm{G}(\%)$ \\
\hline Rédeas & 160 & $160(100)$ & $0(0)$ & $0(0)$ \\
Apartação & 160 & $160(100)$ & $0(0)$ & $0(0)$ \\
Tambor/baliza & 160 & $160(100)$ & $0(0)$ & $0(0)$ \\
Corrida & 160 & $160(100)$ & $0(0)$ & $0(0)$ \\
Conformação & 101 & $70(69,3)$ & $29(28,7)$ & $2(1,98)$ \\
Total & 741 & $710(95,82)$ & $29(3,91)$ & $2(0,27)$ \\
\hline
\end{tabular}

$\mathrm{N}$ : número de animais testados, C/C: cavalos homozigotos normais, C/G: animais heterozigotos para HYPP, G/G: animais homozigotos para HYPP. 
No Brasil, desde primeiro de julho de 2004, todos os QM descendentes do garanhão "Impressive", obrigatoriamente, necessitam do teste genético e o resultado deve constar no registro do animal e, desde primeiro de julho de 2007, está proibido o registro de animais homozigotos para a enfermidade. Essas medidas foram adotadas visando a diminuir a prevalência da mutação (ABQM, 2014). Neste estudo, a prevalência da enfermidade foi de $22,9 \%$ para os animais nascidos até 2004 e de $37,7 \%$ para os nascidos a partir de 2005, o que demonstra que a medida de controle imposta pode não estar sendo eficaz para diminuir a prevalência da enfermidade. Talvez a maior dificuldade para se controlar a HYPP, como já mencionado, seja o sucesso obtido por cavalos positivos nas competições em que participam (NAYLOR, 1994b). A existência de animais positivos em 53,8\% dos locais onde as amostras de animais de conformação foram colhidas reforça a necessidade de novas medidas de controle.

\section{CONCLUSÃO}

A elevada prevalência de HYPP observada nos animais de conformação evidencia a importância da enfermidade no contexto do mercado do cavalo QM desta linhagem. O fato de a mutação ter sido identificada em 53,8\% das propriedades onde amostras desta categoria foram colhidas indica que a presença do alelo mutante pode não estar sendo considerado durante a escolha dos acasalamentos, o que pode levar a um aumento significativo do número de cavalos afetados pela enfermidade. Os achados deste estudo indicam que a medida adotada para diminuir a prevalência da enfermidade pode não estar sendo eficaz, o que torna necessária a adoção de outras estratégias para diminuir a prevalência da mutação.

\section{AGRADECIMENTO}

À Fundação de Apoio a Pesquisa do Estado de São Paulo (FAPESP), pelo suporte financeiro em forma de auxílio regular à pesquisa (processo 2011/23729-0).

\section{COMITÊ DE ÉTICA E BIOSSEGURANÇA}

Os procedimentos realizados foram previamente aprovados pela Câmara de Ética em Experimentação Animal institucional (Protocolo n.262/2011-CEUA).

\section{REFERÊNCIAS}

ABQM (ASSOCIAÇÃO BRASILEIRA DE CRIADORES DE CAVALOS QUARTO DE MILHA). Disponível em: $<$ http://abqm. com.br/index.php?option $=$ com_content $\&$ view $=$ article $\&$ id $=8 \&$ Ite mid $=2>$. Acesso em 03 de jul. 2014 .

FINNO, C.J. et al. Equine diseases caused by know genetic mutations. Veterinary Journal, v.179, p.336-347, 2009. Disponível em: <http://ac.els-cdn.com/S1090023308001275/1s2.0-S1090023308001275-main.pdf? tid=968caf9c-2c51-11e4b2d3-00000aab0f6b\&acdnat $=1408969145 \_96261872 \mathrm{f3b} 1 \mathrm{a} 6 \mathrm{c} 0$ 58a5d8e2ce1843fe >. Acesso em: 10 jun. 2014. doi: 10.1016/j. tvj1.2008.03.016.

GARCIA, J.F. et al. Utilização de marcadores de DNA para o diagnóstico genômico de animais domésticos: 2. Detecção da mutação pontual causadora da paralisia hipercalêmica periódica (HYPP) em equinos da raça Quarto de Milha. Brazilian Journal of Veterinary Research and Animal Science, v.33, n.3, p.136139, 1996. Disponível em: <file:///C:/Users/Downloads/5018162050-1-PB\%20(2).pdf>. Acesso em: 20 abr. 2014.

MEYER, T.S. et al. Hyperkalaemic periodic paralysis in horses: a review. Equine Veterinary Journal. v.31, n.5, p.362367, 1999. Disponível em: <http://onlinelibrary.wiley.com/ doi/10.1111/j.2042-3306.1999.tb03834.x/pdf>. Acesso em: 20 abr. 2014. doi: 10.1111/j.2042-3306.1999.tb03834.x

NAYLOR, J.M. Equine hiperkalemic periodic paralysis: Review and implications. Canadian Veterinary Journal, v.35, p.279285, 1994a.

NAYLOR, J.M. et al. Inheritance of myotonic discharges in American Quarter Horse and the relations to hyperkalemic periodic paralysis. Canadian Journal of Veterinary Research, v.56, p.62-66, 1992.

NAYLOR, J.M. Selection of Quarter Horse affected with hyperkalemic periodic paralysis by show judges. Journal of the American Veterinary Research, v.204, n.6, p.926-928, 1994b.

RUDOLPH, J.A. et al. Periodic paralysis in Quarter Horses: a sodium channel mutation disseminated by selective breeding. Nature Genetics, v.2, p.144-147, 1992. Disponível em: <http:// www.nature.com/ng/journal/v2/n2/pdf/ng1092-144.pdf $>$. Acesso em: 20 abr. 2014. doi: 10.1038/ng1092-144.

SPIER, S.J. Hyperkalemic periodic paralysis: 14 years later. AAEP Proceedings, v.52, p.347-350, 2006. Disponível em: <http:// www.ivis.org/proceedings/aaep/2006/pdf/z9100106000347. pdf?origin=publication_detail $>$. Acesso em: 20 abr. 2014.

STEISS, J.E.; NAYLOR, J.M. Episodic muscle tremors in a Quarter Horse: Resemblance to hyperkalemic periodic paralysis. Canadian Veterinary Journal. v.27, p.332-335, 1986. Disponível em: <http://www.ncbi.nlm.nih.gov/pmc/articles/PMC1680300/pdf/ canvetj00597-0054.pdf>. Acesso em: 20 jun. 2014.

TRYON, R.C. et al. Evaluation of allele frequencies of inherited disease genes in subgroups of American Quarter Horses. Journal of the American Veterinary Medical Association, v.234, p.120125, 2009. Disponível em: <http://avmajournals.avma.org/doi/ abs/10.2460/javma.234.1.120>. Acesso em: 19 jun. 2014. doi: 10.2460/javma.234.1.120.

ZORDAN, P.A.L. Levantamento da frequência da alelo mutante causador da paralisia periódica hipercalêmica (HYPP) em cavalos da raça Quarto de Milha. 2000. $26 \mathrm{f}$. Dissertação (Mestrado em Zootecnia) - Universidade Federal de Minas Gerais, Escola de Veterinária, Belo Horizonte, MG. 